\title{
Diversidade e comunicação: percepções de surdos sobre atividade de educação em saúde realizada por estudantes de medicina
}

\author{
Diversity and communication: perceptions of deaf on the activity of health \\ education carried out by medical students
}

\section{Diversidad y comunicación: percepciones de sordos acerca de una actividad de educación en salud realizada por estudiantes de medicina}

\author{
Bianca Pereira Rodrigues Yonemotu ${ }^{1, a}$ \\ biancaelaura@gmail.com | http://orcid.org/oooo-0003-0908-4223 \\ Camila Mugnai Vieira ${ }^{1, b}$ \\ camilamugnai@gmail.com | http://orcid.org/oooo-0oo1-7564-6218 \\ ${ }^{1}$ Faculdade de Medicina de Marília. Marília, SP, Brasil. \\ a Mestre em Ensino e Saúde pela Faculdade de Medicina de Marília. \\ ${ }^{\text {b }}$ Doutorado em Educação pela Universidade Estadual Paulista.
}

\section{Resumo}

A comunidade surda possui cultura e linguagem próprias, desconhecidas pela maioria dos ouvintes, o que a exclui de vários processos da sociedade. As barreiras na comunicação e o preconceito dificultam seu acesso a serviços de saúde. Analisou-se a vivência de uma atividade prática de Educação em Saúde com 19 surdos feita por 20 estudantes do primeiro ano de um curso de medicina. Após um curso de Língua Brasileira de Sinais, os estudantes realizaram uma atividade junto aos surdos, na qual apresentaram palestras sobre temas de saúde e interagiram em ações como aferição da pressão e cálculo do Índice de Massa Corporal. Posteriormente, os surdos participaram de dois grupos focais para relatarem sua experiência. A análise dos dados deu-se pelo Discurso do Sujeito Coletivo. Os surdos ficaram satisfeitos com a interação, relataram preocupação com prevenção e autocuidado e expectativas positivas quanto à formação de médicos humanizados e qualificados para seu atendimento.

Palavras-chave: Educação médica; Humanização da assistência; Relações médico-paciente; Comunicação; Surdez.

\begin{abstract}
The deaf community has its own culture and language, unknown to most listeners, which excludes it from various societal processes. Communication barriers and prejudice hinder access to health services. The experience of a practical activity of Health Education made with 19 deaf people by 20 students from the first year of a medical course was analyzed. After a course in Brazilian Sign Language, students performed
\end{abstract}


an activity with the deaf, in which they presented lectures on health topics and interacted in actions such as pressure measurement and calculation of the Body Mass Index. Subsequently, the deaf participated in two focus groups to report their experience. The analysis of the data was given by the Discourse of Collective Subject. Deaf people were satisfied with the interaction, reported concern about prevention and self-care and positive expectations regarding the training of humanized and qualified doctors for their care.

Keywords: Medical education; Humanization of assistance; Physician-patient relations; Communication; Deafness.

\section{Resumen}

La comunidad sorda posee cultura y lenguaje propios, desconocidos por la mayoría de los oyentes, lo que la excluye de varios procesos de sociedad. Barreras en comunicación y prejuicio dificultan su acceso a servicios de salud. Se analizó la vivencia de una actividad práctica de Educación en Salud, hecha por 20 estudiantes del primer año de un curso de medicina con 19 sordos. Después de un curso de Lengua Brasileña de Señales, los estudiantes realizaron una actividad con estos, en que presentaron charlas sobre temas de salud e interactuaron en acciones como medición de presión y cálculo del Índice de Masa Corporal. Posteriormente, participaron de dos grupos focales para relatar su experiencia. El análisis de datos se dio por Discurso del Sujeto Colectivo. Los sordos quedaron satisfechos con la interacción, relataron preocupación con prevención, autocuidado y expectativas positivas cuanto a la formación de médicos humanizados y calificados para su atención.

Palabras clave: Educación médica; Humanización de la atención; Relaciones médico-paciente; Comunicación; Sordera.

Contribuição dos autores: ambas as autoras contribuíram para todas as etapas do estudo e manuscrito.

Declaração de conflito de interesses: não há.

Considerações éticas: o projeto foi encaminhado para o Comitê de Ética e Pesquisa com seres Humanos da Faculdade de Medicina de Marília (Famema) sob o parecer n. ${ }^{\circ}$ 2.517.922, e após aprovação, os participantes assinaram o Termo de consentimento livre e esclarecido.

Fontes de financiamento: não houve.

Agradecimento/Contribuições adicionais: não há.

Histórico do artigo: submetido: 27 jun. 2019 | aceito: 26 abr. 2020 | publicado: 30 jun. 2020.

Apresentação anterior: não há.

Licença CC BY-NC atribuição não comercial. Com essa licença é permitido acessar, baixar (download), copiar, imprimir, compartilhar, reutilizar e distribuir os artigos, desde que para uso não comercial e com a citação da fonte, conferindo os devidos créditos de autoria e menção à Reciis. Nesses casos, nenhuma permissão é necessária por parte dos autores ou dos editores. 


\section{Introdução}

A saúde não pode ser entendida apenas como a ausência da doença, mas como um estado de bem-estar físico, mental e social que se traduz, ainda, na qualidade de vida do indivíduo. É um direito fundamental do ser humano que deve ser garantido pelo Estado ${ }^{1-2}$.

Em 1990, foi regulamentado o Sistema Único de Saúde (SUS), com os princípios de universalidade, equidade e integralidade. Esses princípios se traduzem na oferta de ações e serviços sem distinção, respeitando, portanto, as especificidades de cada indivíduo, dando prioridade aos mais vulneráveis e atendendo a todos em suas necessidades ${ }^{3}$.

Além da atenção ao cuidado individual, o SUS pressupõe ações de cuidado coletivo, com enfoque em processos de educação em saúde, visando à prevenção e a promoção de saúde ${ }^{4}$.

Em meio à população, há diversos grupos de pessoas com suas especificidades, as quais devem ser respeitadas durante os atendimentos em saúde. Algumas destas especificidades podem afetar intensamente a comunicação e a relação entre os profissionais de saúde e os pacientes, como no caso dos surdos.

A surdez se caracteriza pela perda menor ou maior da capacidade normal de percepção dos sons. Ela tem graus que se dividem em leve, moderado, severo e profundo, os quais são descritos de acordo com a quantidade de decibéis que o indivíduo não percebe ${ }^{5}$.

Segundo o censo do Instituto Brasileiro de Geografia e Estatística (IBGE), em 2010, havia cerca de 10 milhões de indivíduos com surdez nos diferentes graus no Brasil ${ }^{6}$.

Os surdos que são usuários das línguas de sinais possuem uma cultura própria, na qual a falta da audição promove uma forma particular de experimentar o mundo e se situar nele e a língua de sinais faz parte de sua identidade ${ }^{7}$.

A comunicação é uma necessidade do ser humano. Também se configura como parte da história e da cultura de um indivíduo. A comunicação entre as pessoas é uma troca de sentimentos e necessidades e por meio dela é possível perceber a realidade do outro, suas crenças, seus valores, sua subjetividade ${ }^{8-9}$.

A humanização da atenção à saúde depende do estabelecimento da comunicação entre profissionais de saúde e todos os usuários, respeitando suas especificidades, sua cultura e sua identidade. Nesse sentido, é essencial a ampliação de acesso da população surda aos serviços de saúde ${ }^{10}$.

Educar em saúde a comunidade surda é uma forma de tirar esses indivíduos da situação de vulnerabilidade, ampliando o acesso a informações, compreensão e envolvimento no processo de cuidado em saúde, gerando possibilidade de maior autonomia para este grupo de pessoas. Educar também é humanizar.

No que tange à população surda, a Lei n. ${ }^{0} 10.098$, de 19 de dezembro de $2000^{2}$, buscou promover a acessibilidade por meio da retirada de obstáculos e barreiras existentes nos meios de comunicação. A Língua Brasileira de Sinais (Libras), que é a língua materna dos surdos, foi reconhecida como a segunda língua oficial do Brasil em 24 de abril de 2002, por meio da Lei n. ${ }^{0} 10.436^{11} \mathrm{e}$, em 22 de dezembro de 2005 , o Decreto $n .{ }^{0} 5 \cdot 626^{12}$ regulamentou essa lei.

Mesmo com algumas conquistas legais, essa população ainda sofre por causa de barreiras comunicacionais, falta de informação e preconceito. A sociedade cria regras e normas que definem os padrões de normalidade por meio de ideias preconcebidas. Assim, define grupos de pessoas mais ou menos aceitos, e criam-se os estereótipos. Essa padronização não é necessariamente justa ou verdadeira, pois é resultante de expectativas e carregada de valores e julgamentos, além de falta de conhecimento ${ }^{13}$.

Este movimento de exclusão ocorre em diferentes esferas da sociedade, inclusive na área da Saúde. Os surdos são, de certa forma, excluídos neste âmbito. A diferença linguística se constitui numa barreira, assim como a falta de confiança nos profissionais ouvintes e a ideia, por parte desses, de que o surdo é menos inteligente ${ }^{14}$. 
As dificuldades de comunicação trazem inúmeras consequências negativas tanto para o surdo, que tem pouca informação em relação à sua saúde, quanto para os trabalhadores que o atendem, que na maioria das vezes, por não serem capacitados para se comunicarem com este público, sentem-se angustiados nas situações de contato com estes usuários. Essas interações causam desconforto, medo, desconfiança, entre outros sentimentos ruins, que podem atrapalhar os atendimentos e cuidados em saúde ${ }^{15}$. Um dos resultados disso é a baixa procura pelo cuidado em saúde por parte dos surdos, além de casos em que, apesar de atendidos, os surdos continuaram com dúvidas a respeito de seu diagnóstico e tratamento, bem como expressaram insatisfação com relação aos serviços de saúde ${ }^{16-17}$.

Os surdos são, portanto, considerados sujeitos passivos no processo de cuidado em saúde que têm pouca autonomia e responsabilidade nesse processo, pois, na maioria das vezes, precisam de um intérprete ou de algum conhecido como interlocutor das conversas, não tendo preservada sua privacidade ${ }^{18}$.

O presente estudo é um recorte da dissertação de mestrado da primeira autora, orientada pela segunda ${ }^{19}$, que teve o objetivo de analisar os efeitos de um curso de Libras nas atitudes sociais de estudantes de Medicina em relação à inclusão e os efeitos nas concepções e nos sentimentos de estudantes e surdos em relação à comunicação estabelecida entre eles. Este artigo, especificamente, centra-se na percepção dos surdos sobre a vivência de uma atividade prática de Educação em Saúde realizada por estudantes de medicina de uma cidade do interior paulista ao final de um curso de Libras.

\section{Método}

Tratou-se de um estudo qualitativo, do qual participaram 19 surdos de uma cidade do interior paulista, com idades entre 25 e 64 anos, média de 44,7 anos e desvio padrão 9,55 anos. Esse grupo foi composto por 12 mulheres e 7 homens, todos com surdez bilateral e que utilizam a Libras para comunicação. Também participaram 20 estudantes do primeiro ano de medicina de uma faculdade do interior paulista, com média de idade de 20,6 anos e desvio padrão de 1,9 anos, sendo 14 homens e 13 mulheres.

A pesquisa se desenvolveu na sede da comunidade dos surdos, devido à facilidade de acesso e onde a primeira autora é intérprete há 11 anos, já tendo um vínculo bem estabelecido, o que facilitou a coleta de dados.

Após passarem por um curso de Libras composto por 11 encontros de uma hora e meia cada e com metodologias ativas de ensino e aprendizagem, os estudantes de medicina realizaram como conclusão do curso uma atividade prática de Educação em Saúde junto aos surdos com duração de duas horas. O curso foi ministrado pela primeira autora. Os estudantes receberam informações acerca da Libras e da cultura surda, elaboraram e treinaram palestras sobre assuntos tais como, queimaduras, ressuscitação cardiopulmonar, engasgo e importância do exercício físico para a saúde. No dia da atividade prática, cada palestra teve a duração aproximada de 15 minutos e foram todas apresentadas pelos estudantes, aos surdos, em Libras. Após as explicações dos temas, os surdos puderam fazer perguntas sobre esses e outros assuntos. Esse momento foi interpretado pela primeira autora e por outros intérpretes, previamente selecionados e preparados para tal.

Na sequência das palestras, os estudantes fizeram aferição de pressão dos surdos e cálculo do Índice de Massa Corporal (IMC). Essa parte da atividade teve o intuito de ampliar a interação dos estudantes com os surdos, para que pudessem conversar em Libras livremente e sem a interferência da pesquisadora ou de outros intérpretes, a não ser quando solicitado. Os assuntos abordados nesse contato foram diversos, desde os dados de identificação, hábitos de vida e situações de saúde dos surdos e familiares.

Após a atividade prática, realizaram-se dois encontros de grupo focal com os surdos. Grupo focal é uma técnica de pesquisa qualitativa que coleta os dados por meio da interação de pessoas em um grupo. Busca 
obter informações para compreender crenças, atitudes e percepções sobre um determinado tema ou foco específico ${ }^{20}$.

Os surdos foram divididos em dois grupos, um com cinco e outro com oito participantes, de acordo com sua disponibilidade de horários. Os encontros dos grupos focais aconteceram em dois sábados, com intervalo de uma semana de um para o outro e tiveram duração de 30 minutos cada. Foram mediados por uma intérprete previamente selecionada e preparada para esse momento e foram filmados. A condução dos encontros foi feita a partir de um roteiro composto por questões norteadoras, previamente elaborado pelas autoras, que abordava temas como os sentimentos vivenciados no contato com os estudantes, sua percepção da comunicação estabelecida e possíveis repercussões da intervenção em sua busca por serviços de saúde.

A intérprete começava com uma pergunta norteadora e, a partir das respostas dadas pelos surdos, ia aprofundando os assuntos relacionados ao questionamento. Quando as respostas pareciam estar saturadas, ou seja, quando não surgiam novos conteúdos, a intérprete passava para outra pergunta, até que todos os assuntos fossem abordados.

Ao criar a oportunidade para que os surdos expressem suas experiências, sentimentos e impressões a partir da vivência da interação com os estudantes, eles são valorizados como protagonistas deste processo, ouvidos, mesmo que em outra língua e forma de comunicação, em relação ao que pensam e sentem.

Optou-se pela técnica de grupo focal com os surdos nesta fase para que se pudessem captar sensações, sentimentos e opiniões de forma mais ampliada. Em experiências anteriores das próprias pesquisadoras em coleta de dados com surdos, nas quais utilizaram entrevistas individuais interpretadas em Libras, a maioria dos surdos mostrou-se lacônica em suas respostas, possivelmente deixando de expressar, portanto, informações que podem ser importantes para a análise posterior. Na literatura, o uso de grupos focais como procedimento de coleta de dados com surdos é quase inexistente. Freitas utilizou essa técnica em seu estudo e obteve êxito ${ }^{21}$. A experiência da pesquisadora intérprete de Libras no convívio diário com surdos indicava que, quando em grupo com outros surdos, as conversas costumavam fluir mais naturalmente, com mais conteúdos expressos e de modo mais aprofundado do que no contato individual com a intérprete. A coleta de dados com esse procedimento confirmou essa hipótese aventada empiricamente, tendo o grupo focal se mostrado um método eficiente de coleta de dados com os surdos participantes, pois permitiu acesso ao material necessário para atingir o objetivo proposto.

As filmagens dos grupos focais foram transcritas para o português e analisadas a partir do Discurso do Sujeito Coletivo (DSC). Essa técnica de análise permite sintetizar num único discurso elaborado em primeira pessoa do singular a opinião de diferentes depoimentos, mas que contém sentidos parecidos. Nesse discurso síntese, a fala de um representa a fala da coletividade ${ }^{22}$.

Os resultados obtidos a partir da análise dos grupos focais foram organizados em eixos temáticos a partir das questões disparadoras do roteiro utilizado para a coleta de dados e na condução dos grupos. Os eixos elencados foram: 1) Sentimentos relacionados ao contato com os estudantes de Medicina durante a atividade prática; 2) Comunicação estabelecida com os estudantes; 3) Compreensão acerca dos assuntos abordados; 4) Mudança na busca pelos serviços de saúde e 5) Sugestões para atividades futuras de Educação em Saúde.

Após a transcrição das filmagens feitas dos grupos focais, a pesquisadora fez repetidas leituras a fim de encontrar as Expressões Chave (EC) dos sujeitos. Nessas EC foram identificadas as Ideias Centrais (IC), que posteriormente foram organizadas em Ancoragens. A partir dessas Ancoragens, foram construídos quadros com os respectivos discursos. Ao final, todos os discursos foram integrados em um único DSC, que articula todas as ancoragens e ICs expressas por todos os participantes, sem que nenhuma delas seja excluída do resultado final. 


\section{Resultados}

Os resultados são apresentados por meio dos quadros para cada eixo temático, que expressam as EC, as ICs e as Ancoragens encontradas a partir da análise dos grupos focais com os surdos. Após cada quadro, é apresentado o DSC específico referente àquele tema. Posteriormente, é apresentado o DSC final.

O Quadro 1 apresenta os sentimentos em relação à visita dos estudantes.

Quadro 1 - Sentimentos relacionados ao contato com os estudantes de Medicina durante a atividade prática de Educação em Saúde

\begin{tabular}{|c|c|c|}
\hline Expressões chave & Ideias centrais & Ancoragens \\
\hline "É muito bom aprender! É muito bom!!" & - Bom aprender & \\
\hline $\begin{array}{l}\text { "[...] é muito bom quando os estudantes } \\
\text { vêm aqui explicar de saúde. Nós } \\
\text { precisamos aprender mais e mais para } \\
\text { desenvolver. Para os surdos é difícil } \\
\text { (o acesso a informações) então temos } \\
\text { dúvida e eles vem aqui explicar[...]." }\end{array}$ & $\begin{array}{l}\text { - Necessidade de aprender } \\
\text { sobre saúde } \\
\text { - Dificuldades de acesso a } \\
\text { informações }\end{array}$ & $\begin{array}{l}\text { - Necessidade e possibilidade de } \\
\text { aprender sobre saúde (S.10a, } \\
\text { S.16a, S.16b, S.4a) }\end{array}$ \\
\hline "Visita muito boa!!" & $\begin{array}{l}\text { - Satisfação com a visita dos } \\
\text { estudantes }\end{array}$ & $\begin{array}{l}\text { - Satisfação com a visita e em } \\
\text { ver estudantes falando em } \\
\text { Libras (S.3a, S.14a) }\end{array}$ \\
\hline $\begin{array}{l}\text { "[...] uma moça (estudante) interpretou } \\
\text { em libras e ensinou. Ela está de } \\
\text { parabéns. Eu fiquei muito feliz. Ela será } \\
\text { uma médica melhor no futuro." }\end{array}$ & $\begin{array}{l}\text { - Felicidade em ver o estudante } \\
\text { interpretando em Libras } \\
\text { - Expectativa de formação de } \\
\text { médicos mais humanizados }\end{array}$ & $\begin{array}{l}\text { - Expectativa de formação de } \\
\text { médicos mais humanizados } \\
\text { (S.14b) }\end{array}$ \\
\hline $\begin{array}{l}\text { "Gostei da visita porque entendemos as } \\
\text { coisas que eles explicaram." }\end{array}$ & - Bom aprender & \\
\hline
\end{tabular}

Fonte: Dados da pesquisa (2019).

"Para os surdos, é difícil o acesso a informações sobre saúde, por isso temos muitas dúvidas. Receber os estudantes de Medicina e vê-los falando em Libras é uma oportunidade de aprender mais e de percebermos que eles serão melhores médicos no futuro."(DSC1)

O Quadro 2 mostra como foi a comunicação estabelecida pelos estudantes e surdos durante a atividade prática, segundo os surdos.

Quadro 2 - Comunicação estabelecida com os estudantes de Medicina

(continua)

\begin{tabular}{|l|l|l|}
\hline Expressões chave & Ideias centrais & Ancoragens \\
\hline $\begin{array}{l}\text { "Eu entendi bem porque estavam } \\
\text { interpretando a palestra." }\end{array}$ & $\begin{array}{l}\text { - Acessibilidade na } \\
\text { apresentação }\end{array}$ & \\
\hline $\begin{array}{l}\text { "Aqui os estudantes conversaram com } \\
\text { a gente. Aqui foi muito mais fácil (a } \\
\text { comunicação) porque eles sabiam um } \\
\text { pouco de Libras." }\end{array}$ & $\begin{array}{l}\text { - Estabelecimento de } \\
\text { comunicação efetiva } \\
\text { - Satisfação em ver os } \\
\text { estudantes se comunicando } \\
\text { em Libras }\end{array}$ & $\begin{array}{l}\text { - Conteúdos acessíveis por meio } \\
\text { da Libras (S.14a) }\end{array}$ \\
\hline
\end{tabular}




\begin{tabular}{|l|l|l|}
\hline Expressões chave & Ideias centrais & Ancoragens \\
\hline $\begin{array}{l}\text { "Os estudantes olharam pra nós e sabiam } \\
\text { um pouco de Libras." }\end{array}$ & $\begin{array}{l}\text { - Contato visual } \\
\text { - Conversação em Libras }\end{array}$ & $\begin{array}{l}\text { - Satisfação com o contato } \\
\text { visual e em ver os estudantes se } \\
\text { comunicado em Libras } \\
\text { (S.9a, S.9b, S.8a, S.8b, S.16a, } \\
\text { S.16c, S.10b) }\end{array}$ \\
\hline $\begin{array}{l}\text { Libras, mas a comunicação ainda é } \\
\text { difícil. Precisou da ajuda de intérprete. O } \\
\text { estudante ficava ao lado do intérprete e } \\
\text { quando precisava o intérprete ajudava... } \\
\text { eles (os estudantes) olharam para mim e } \\
\text { não para intérprete." }\end{array}$ & $\begin{array}{l}\text { - Comunicação difícil e } \\
\text { intermediada por intérprete } \\
\text { - Contato visual }\end{array}$ & $\begin{array}{l}\text { - Comunicação é difícil e precisa } \\
\text { da intermediação do intérprete }\end{array}$ \\
\hline $\begin{array}{l}\text { (S.16b, S.10a) } \\
\text { "O estudante falou comigo. Precisou de } \\
\text { de Libras, mas conseguiu conversar } \\
\text { comigo. Aprendi com eles naquele dia." }\end{array}$ & $\begin{array}{l}\text { - Comunicação intermediada } \\
\text { por intérprete } \\
\text { - Estudantes sabem Libras }\end{array}$ & $\begin{array}{l}\text { - Aprendizado na interação } \\
\text { (S.10c) }\end{array}$ \\
\hline
\end{tabular}

Fonte: Dados da pesquisa (2019).

"A palestra ter sido interpretada em Libras pelos estudantes facilitou nosso entendimento. Foi bom quando os estudantes se comunicaram conosco em Libras enquanto olhavam nos nossos olhos. Mesmo que a comunicação tenha sido meio difícil e tenha precisado da ajuda de intérprete, eles conseguiram conversar."(DSC2)

O Quadro 3 apresenta essa compreensão dos surdos em relação aos assuntos abordados pelos estudantes.

Quadro 3-Compreensão acerca dos assuntos abordados pelos estudantes

\begin{tabular}{|c|c|c|}
\hline Expressões chave & Ideias centrais & Ancoragens \\
\hline $\begin{array}{l}\text { "[...] eles (estudantes) explicaram } \\
\text { sobre diabetes, pressão arterial, falta } \\
\text { de ar e RCP[...]." }\end{array}$ & $\begin{array}{l}\text { - Os temas abordados nas } \\
\text { palestras e durante a interação } \\
\text { com os surdos }\end{array}$ & $\begin{array}{l}\text { - Lembrança dos temas abordados } \\
\text { nas palestras e na interação } \\
\text { (S.16a, S.18a, S.10a) }\end{array}$ \\
\hline "Diabetes e pressão alta" & - Temas da palestra e da interação & \\
\hline $\begin{array}{l}\text { "Exame de saúde é bom fazer } \\
\text { sempre." }\end{array}$ & - Importância da prevenção & \\
\hline $\begin{array}{l}\text { "Precisa cuidar da saúde, cuidar do } \\
\text { corpo... eu nunca tinha visto como } \\
\text { faz RCP e nem como faz no caso de } \\
\text { engasgo. Como foi a primeira vez } \\
\text { que eu vi, eu não tenho coragem de } \\
\text { ajudar se alguém precisar." }\end{array}$ & $\begin{array}{l}\text { - Necessidade de prevenção } \\
\text { - Conceitos novos } \\
\text { - Necessidade de aprender mais }\end{array}$ & $\begin{array}{l}\text { - Importância e necessidade de } \\
\text { fazer a prevenção (S.3a, S.14a) }\end{array}$ \\
\hline $\begin{array}{l}\text { "Explicaram de diabetes, } \\
\text { queimaduras e regime." }\end{array}$ & - Temas da palestra e da interação & \\
\hline $\begin{array}{l}\text { "Aprendi que precisa passar pomada } \\
\text { na queimadura e depois ir ao médico. } \\
\text { Não pode passar pasta de dente." }\end{array}$ & $\begin{array}{l}\text { - Aprendizado com os conteúdos } \\
\text { apresentados }\end{array}$ & $\begin{array}{l}\text { - Aprendizado de conteúdos novos } \\
\text { e necessidade de aprender mais } \\
\text { (S.14b, S.14c, S.15a) }\end{array}$ \\
\hline
\end{tabular}

Fonte: Dados da pesquisa (2019). 
"Os temas abordados nas palestras e na interação foram queimaduras, ressuscitação e falta de ar, diabetes e pressão arterial. Alguns desses temas eram novos para nós e por isso precisam ser explicados mais vezes. Essas palestras também nos fizeram entender melhor a importância e a necessidade de se fazer a prevenção.”(DSC3)

O Quadro 4 mostra os resultados obtidos após a atividade de Educação em Saúde em relação à mudança de pensamento na busca pelos serviços de saúde.

Quadro 4 - Mudança na busca pelos serviços de saúde após a atividade de Educação em Saúde

\begin{tabular}{|c|c|c|}
\hline Expressões chave & Ideias centrais & Ancoragens \\
\hline $\begin{array}{l}\text { "Eu já vou sempre ao médico fazer } \\
\text { prevenção e não só quando estou } \\
\text { doente." }\end{array}$ & $\begin{array}{l}\text { - Já sabe da importância da } \\
\text { prevenção }\end{array}$ & $\begin{array}{l}\text { - A prevenção é importante } \\
\text { (S.16a, S.6a, S.3a) }\end{array}$ \\
\hline $\begin{array}{l}\text { "Vou ao médico uma vez por ano fazer } \\
\text { exames." } \\
\text { "Eu vou ao médico, mas ele não tem } \\
\text { paciência de explicar. Como nem } \\
\text { sempre tem intérprete disponível } \\
\text { ele começa a fechar a cara e fica } \\
\text { nervoso... eu também fico. Todos nós } \\
\text { (surdos) queremos ir mais ao médico, } \\
\text { mas a comunicação é difícil. Não tem } \\
\text { entendimento. Eu percebo no rosto } \\
\text { dele que fica impaciente com surdos } \\
\text { que usam a Libras... eu também fico } \\
\text { nervosa." }\end{array}$ & $\begin{array}{l}\text { - Prevenção } \\
\text { - Vontade de buscar mais os } \\
\text { serviços de saúde } \\
\text { - Dificuldade de acesso aos } \\
\text { serviços de saúde }\end{array}$ & $\begin{array}{l}\text { - Vontade de buscar mais os } \\
\text { serviços de saúde (S.6b) }\end{array}$ \\
\hline "Exame de saúde é bom fazer sempre." & - Importância da prevenção & $\begin{array}{l}\text { - Serviços de saúde inacessíveis } \\
\text { pela falta de comunicação (S.6c) }\end{array}$ \\
\hline $\begin{array}{l}\text { "...meu ginecologista sabe um pouco de } \\
\text { Libras e gosta dos surdos, então eu só } \\
\text { gosto de ir lá fazer meus exames." }\end{array}$ & $\begin{array}{l}\text { - Preferência em fazer a } \\
\text { prevenção com o médico que sabe } \\
\text { se comunicar em Libras }\end{array}$ & $\begin{array}{l}\text { D. Preferência por fazer a } \\
\text { prevenção com profissionais que } \\
\text { sabem Libras (S.5a) }\end{array}$ \\
\hline
\end{tabular}

Fonte: Dados da pesquisa (2019).

"A prevenção é importante, e os surdos têm vontade de buscar mais os serviços de saúde, mas a comunicação com os profissionais é difícil. Os profissionais e os surdos ficam nervosos nessas situações, então é preferível fazer os exames de prevenção com médicos que sabem Libras, mesmo que pouco." (DSC4) 
O Quadro 5 aponta alguns temas que os surdos gostariam que fossem abordados em atividades futuras. Quadro 5 - Sugestão para futuras atividades de Educação em Saúde

\begin{tabular}{|l|l|l|}
\hline Expressões chave & Ideias centrais & Ancoragens \\
\hline $\begin{array}{l}\text { "Quero aprender sobre minha saúde, } \\
\text { colesterol e diabetes." }\end{array}$ & $\begin{array}{l}\text { - Vontade de aprender mais } \\
\text { sobre os temas da palestra }\end{array}$ & $\begin{array}{l}\text { - Desejo de aprender mais } \\
\text { sobre os temas da palestra } \\
\text { (S.16a, S.10a, S.14a) }\end{array}$ \\
\hline $\begin{array}{l}\text { "Relação do emocional com diabetes e } \\
\text { pressão." }\end{array}$ & $\begin{array}{l}\text { - Relação do emocional com } \\
\text { algumas doenças }\end{array}$ & \\
\hline "Alimentação e saúde." & - Alimentação saudável & \\
\hline $\begin{array}{l}\text { "Às vezes temos problemas emocionais e } \\
\text { precisamos de apoio psicológico. É difícil } \\
\text { levar intérprete nesses atendimentos. } \\
\text { Queria saber sobre coisas emocionais[...]." }\end{array}$ & - Ajuda psicológica e acessível & $\begin{array}{l}\text { - Necessidade de ajuda } \\
\text { psicológica e acessível } \\
\text { (S.4a) }\end{array}$ \\
\hline
\end{tabular}

Fonte: Dados da pesquisa (2019).

"Os surdos têm desejo de aprender mais sobre temas como a diabetes, a pressão arterial e a relação da alimentação e do emocional com as doenças. Além disso, os surdos também têm problemas emocionais e, por isso, precisamos aprender mais sobre as emoções e ter um apoio psicológico acessível.” (DSC 5)

A seguir os discursos de cada eixo temático foram integrados em um só DSC:

"Para os surdos, é difícil o acesso a informações sobre saúde, por isso temos muitas dúvidas. Receber os estudantes de Medicina e vê-los falando em Libras é uma oportunidade de aprender mais e de percebermos que eles serão melhores médicos no futuro!

A palestra ter sido interpretada em Libras pelos estudantes facilitou nosso entendimento. Foi bom quando os estudantes se comunicaram conosco em Libras enquanto olhavam nos nossos olhos. Mesmo que a comunicação tenha sido meio difícil e tenha precisado da ajuda de intérprete, eles conseguiram conversar.

Os temas abordados nas palestras e na interação foram queimaduras, ressuscitação e falta de ar, diabetes e pressão arterial. Alguns desses temas eram novos para nós e por isso precisam ser explicados mais vezes. Essas palestras também nos fizeram entender melhor a importância e a necessidade de se fazer a prevenção.

A prevenção é importante, e os surdos têm vontade de buscar mais os serviços de saúde, mas a comunicação com os profissionais é difícil. Os profissionais e os surdos ficam nervosos nessas situações, então é preferível fazer os exames de prevenção com médicos que sabem Libras, mesmo que pouco.

Os surdos têm desejo de aprender mais sobre temas como a diabetes, a pressão arterial e a relação da alimentação e do emocional com as doenças. Além disso, os surdos também têm problemas emocionais e, por isso, precisamos aprender mais sobre as emoções e ter um apoio psicológico acessível." 


\section{Discussão}

A partir do primeiro DSC apresentado, pode-se perceber a falta de acesso às informações em relação à saúde ${ }^{23-25}$. Essa situação, assim como apontam outros estudos, influencia diretamente no processo saúde-doença ${ }^{24}$. Os surdos procuram menos os serviços de cuidados em saúde, ficando mais vulneráveis ao aparecimento de doenças que não puderam ser detectadas precocemente. Outra consequência da falta de informação é que essa população acaba procurando respostas às suas dúvidas em fontes menos seguras, podendo isso acarretar problemas maiores por causa de informações errôneas. Além disso, a busca por atendimentos de emergência é bem maior, assim como o número de internações hospitalares, se comparados ao público ouvinte ${ }^{24}$.

Ainda no primeiro DSC, os surdos apontam que têm esperança na formação de médicos mais humanizados e capacitados para atendê-los com qualidade e com respeito às suas diferenças. Esse achado evidencia que o cuidado em saúde para o surdo continua sendo um desafio para o SUS. As leis existem, porém, as políticas públicas e as escolas médicas ainda não conseguiram se adequar a tal realidade ${ }^{24}$.

A comunicação direta nos atendimentos em saúde entre surdos e profissionais da saúde é condição fundamental para que o atendimento aconteça em sua integralidade e de forma humanizada ${ }^{25}$.

No segundo discurso, os surdos expressaram que se sentiram bem com o contato visual estabelecido durante a interação com os estudantes, o que nem sempre acontece em relações cotidianas com profissionais da saúde. Pires e Almeida ${ }^{26}$ relataram em seu estudo que profissionais atenderam os surdos se dirigindo aos seus acompanhantes e não a eles.

O cuidado em saúde do surdo feito pelo médico ouvinte se traduz num momento multicultural, pois ambas as culturas estão presentes. Nesse instante, deve ser levada em consideração a bagagem que cada um carrega, seus sentimentos, suas concepções e os significados que atribuem ao contexto socioeconômico cultural no qual estão inseridos ${ }^{27}$.

O fato de os estudantes terem se capacitado na Libras, mesmo que de modo muito inicial, os aproximou um pouco, da cultura dos surdos. Os estudantes perceberam que a interação foi mais humanizada, e possivelmente por isso, imaginaram que, futuramente, poderão se tornar médicos mais inclusivos. Estes resultados vão ao encontro dos achados de Costa e Silva ${ }^{28}$.

Durante a atividade prática de Educação em Saúde, os estudantes explicaram assuntos relacionados a queimaduras, engasgo, ressuscitação cardiopulmonar (RCP) e sobre a importância dos exercícios físicos para a saúde. Os surdos lembraram-se de alguns conteúdos abordados nas palestras, porém pareceu que gravaram mais os assuntos conversados durante o contato direto que tiveram com os estudantes na aferição de pressão e no cálculo do IMC, tais quais diabetes e pressão alta. Apesar da importância atribuída ao acesso a informações básicas às quais não tinham acesso, a interação direta, por meio da conversa com os estudantes, foi ainda mais valorizada.

No terceiro discurso, os surdos apontaram que, por meio das palestras e do contato com os estudantes, obtiveram mais informações sobre a saúde e, como resultado, apresentaram preocupação com o autocuidado e com a prevenção. As campanhas públicas preventivas e de autocuidado precisam ser desenvolvidas de modo a não discriminar as diferenças existentes entre as pessoas. Devem conter ações que integralizem a participação de todos, e, para tal, é necessário que apresentem mais recursos visuais, como legendas, vídeos e desenhos ilustrativos. Dessa maneira, os surdos também serão contemplados ${ }^{23-24}$.

Os surdos entendem a necessidade e a importância da prevenção, como foi explicitado anteriormente, porém relataram no discurso quatro que a falta de comunicação, acompanhada de sentimentos de nervosismo diante das dificuldades de se comunicar, são fatores que os impedem de buscar mais os serviços de saúde. Esses sentimentos também foram encontrados em outras pesquisas ${ }^{26,29}$. 
O entender e ser entendido se traduzem na humanização do serviço de cuidado em saúde. A oferta de cursos de formação e capacitação em Libras para os médicos é urgente e necessária, a fim de diminuir as barreiras de comunicação existentes, além de informar esses profissionais sobre as especificidades linguísticas, culturais e identitárias dos surdos. A língua de sinais, portanto, não deve ser menosprezada.

Ainda nesse discurso, os surdos apontam a preferência por profissionais que saibam Libras, mesmo que minimamente, pois, dessa maneira, conseguem estabelecer um vínculo melhor, ter mais privacidade na consulta e aderir mais facilmente ao cuidado proposto.

Considerando-se a oferta facultativa da disciplina de Libras durante a formação ${ }^{12}$ médica e, por consequência, o pouco conhecimento da cultura do surdo, os intérpretes acabam sendo uma ferramenta utilizada para diminuir os obstáculos de comunicação.

No quinto e último discurso, os participantes apontaram a importância e o desejo de aprenderem mais, assim como mostram outros estudos ${ }^{4}$. Os temas escolhidos por eles para futuras atividades práticas de Educação em Saúde vão ao encontro das suas necessidades pessoais. Como é possível observar, são temas que fazem parte de campanhas públicas preventivas e de autocuidado, mas que aparentemente não são acessíveis a essa população.

Nesse discurso, os surdos também apontaram a necessidade de apoio psicológico. Esses indivíduos enfrentam desafios diários por causa das barreiras de comunicação que encontram em todos os níveis da sociedade. Constroem sua identidade pessoal transitando entre duas culturas diferentes, a dos surdos e a dos ouvintes. A cultura ouvinte construiu um estereótipo de incapacidade para o surdo, que faz com que ele não seja acolhido pela sociedade como um todo. A aquisição da língua de sinais é importante para essa população, pois como seres humanos são seres sociais que necessitam de interação plena com uma comunidade social específica. Os surdos, por viverem numa sociedade hegemonicamente ouvinte, acabam por desenvolver uma identidade flutuante, que não se encaixa bem nem numa cultura, nem na outra, sendo assim, vivem situações de discriminação e isolamento ${ }^{30}$, podendo desenvolver transtornos de ordem emocional.

\section{Considerações finais}

Pode-se constatar dificuldades de acesso dos surdos aos serviços de saúde e à informação, além de que permanecem com dúvidas após os atendimentos, mesmo na presença de intérpretes. As barreiras de comunicação existentes são presentes e colaboram para a marginalização dessa população. A presença do intérprete é importante, porém a capacitação dos médicos é primordial. Os surdos apontaram que preferem ser cuidados pelos profissionais que são capazes de estabelecer comunicação com eles, ainda que básica.

Após a experiência de contato com os estudantes por meio da atividade de Educação em Saúde, os surdos puderam recordar a maior parte dos conteúdos abordados nas palestras dos estudantes e demonstraram preocupação com a prevenção e o autocuidado em saúde.

Momentos da interação mais direta com os estudantes após as palestras, durante as atividades de aferição da pressão arterial e cálculo do IMC, foram relatados com satisfação pelos surdos, animados por verem os estudantes falando diretamente com eles, mantendo contato visual e tentando utilizar a Libras, mesmo que em início de aprendizado.

Além disso, os surdos expressaram expectativas positivas quanto à formação de profissionais de saúde mais humanizados e qualificados para o atendimento dessa população e sugeriram temáticas para serem abordadas em ações futuras de Educação em Saúde.

Um dos pontos marcantes desse estudo foi o uso inovador da técnica de grupos focais para coleta dos dados dos surdos, assim como da técnica do DSC para sua análise. Ambas as técnicas se mostraram 
adequadas no que tange a procedimentos de coleta e de análise de dados junto a essa população, pois conseguiram captar os dados de maneira eficiente e analisá-los de forma integrada.

O curso de Libras ofertado a estudantes de medicina em início de formação - elaborado com foco na saúde, desenvolvido com base nas metodologias ativas de aprendizagem e integrando conhecimentos sobre Libras a uma vivência de interação social entre os estudantes e os surdos - mostrou-se com potencial para repercussões positivas na comunidade surda. Os resultados junto aos estudantes também foram positivos, tendo tornado suas atitudes sociais em relação à inclusão mais positivas, não sendo o foco deste artigo ${ }^{19}$.

Destaca-se a importância da ampliação de pesquisas sobre a temática, que permitam a todos os envolvidos no processo de comunicação expressarem-se e terem suas percepções valorizadas. Ressalta-se também a necessidade de mais intervenções que visem a ampliar a inclusão dos surdos na sociedade, por meio de estratégias para seu empoderamento e desenvolvimento de autonomia. Ações educacionais e de formação de pessoas ouvintes da sociedade como um todo são necessárias, e, mais especificamente neste caso, de estudantes e profissionais de saúde. É relevante proporcionar o acesso à Libras em diferentes níveis de aprofundamento, assim como a informações sobre a comunidade surda, bem como propiciar interações sociais mais frequentes entre surdos e ouvintes, desde cedo e ao longo da vida das pessoas, em diferentes contextos, de modo que ambos passem a conhecerem-se mutuamente em suas diferenças, bem como perceberem similaridades, para que a convivência na diversidade se torne enriquecedora e o processo de inclusão social se efetive.

\section{Referências}

1. Organização Mundial da Saúde. Constituição da Organização Mundial da Saúde (OMS/WHO) 1946 [Constitution of the World Health Organization] [Internet]. São Paulo: Comissão de Direitos Humanos; [199?] [citado em 2020 mar. 21]. Disponível em: https://bit.ly/2zanw8G.

2. Constituição da República Federativa do Brasil: 1988. Brasília (DF): Centro Gráfico do Senado Federal; 1988.

3. Brasil. Ministério da Saúde. SUS: a saúde do Brasil [Internet]. Brasília, DF: O Ministério; 2011 [citado em 2020 mar. 21]. Disponível em: https://bit.ly/3bvMduB.

4. Oliveira YCA, Celino SDM, França ISX, Pagliuca LMF, Costa GMC. Conhecimento e fonte de informações de pessoas surdas sobre saúde e doença. Interface (Botucatu) [Internet]. 2015 jul./set. [citado em 2020 mar 21];19(54):549-60. Disponível em: https://bit.ly/2KnjZXc.

5. Ministério da Educação (BR); Secretaria de Educação Especial. Educação infantil: saberes e práticas da inclusão: dificuldades de comunicação e sinalização: surdez [Internet]. 4. ed. Braślila (DF): O Ministério; 2006 [citado em 2020 mar. 21]. Disponível em: https://bit.ly/3eFNPny.

6. Instituto Brasileiro de Geografia e Estatística. Censo 2010 [Internet]. Brasília, DF: O Instituto; 2010 [citado em 2020 mar. 21]. Disponível em: https://cens02010.ibge.gov.br/.

7. Carvalho AF, Martins VRO. Anunciação e insurreição da diferença surda: contra-ações na biopolítica da educação bilíngue. Childhood Philosophy [Internet] 2016 [citado em 2019 jun. 01];12(24):391-415. doi: https://www.e-publicacoes.uerj.br/index.php/childhood/article/view/22970.

8. Coriolano-Marinus MWL, Queiroga BAM, Ruiz-Moreno L, Lima LS. Comunicação nas práticas em saúde: revisão integrativa da literatura. Saúde Soc [Internet]. 2014 dez. [citado em 2019 fev. 24];23(4):135669. Disponível em: https://bit.ly/3brtZur.

9. Deliberato D. Comunicação alternativa: recursos e procedimentos utilizados no processo de inclusão do aluno com severo distúrbio na comunicação In: Pinho SZ, Saglietti, JRC, organizadores. Núcleos de Ensino. São Paulo: Cultura Acadêmica; 2007, v. 1, p. 366-78.

10. Dias A, Coutinho C, Gaspar D, Moeller L, Mamede M. Libras na formação médica: possibilidade de quebra da barreira comunicativa e melhora na relação médico-paciente surdo. Rev Med [São Paulo] [Internet]. 2017 out.-dez.;96(4):209-14. Disponível em: http://www.revistas.usp.br/revistadc/article/ view/131619. 
11. Presidência da República (BR); Casa Civil; Subchefia para Assuntos Jurídicos. Lei n. ${ }^{0}$ 10.436, de 24 de abril de 2002. Dispõe sobre a Língua Brasileira de Sinais: Libras e dá outras providências. DOU [Internet]. 200224 abr. [citado em 2020 mar. 21]. Disponível em: http://www.planalto.gov.br/ccivil 03/ leis/2002/l10436.htm.

12. Presidência da República (BR); Casa Civil; Subchefia para Assuntos Jurídicos. Decreto n. ${ }^{0}$ 5.626, de 22 de dezembro de 2005. Regulamenta a Lei n. ${ }^{10.436}$, de 24 de abril de 2002, que dispõe sobre a Língua Brasileira de Sinais - Libras, e o art. 18 da Lei n. ${ }^{0} 10.098$, de 19 de dezembro de 2000. DOU [Internet]. 2005 dez. 22. [citado em 2020 mar. 21]. Disponível em: http://www.planalto.gov.br/ccivil 03/ Ato20042006/2005/Decreto/D5626.htm.

13. Baccega MA. O estereótipo e as diversidades. Com Educ [Internet]. 1998 dez. [citado 2019 mar. 01];(13):7-14. Disponível em: http://www.revistas.usp.br/comueduc/article/view/36820.

14. Fernandes EL. Surdez versus aprendizado da língua portuguesa escrita. CES Rev [Internet]. 2008 [citado em 2019 mar. 17];22:77-88. Disponível em: https://bit.ly/2KmUIw3.

15. Tedesco JR, Junges JR. Desafios da prática do acolhimento de surdos na atenção primária. Cad Saúde Pública [Internet]. 2013 ago. [citado em 2020 mar. 17];29(8):1685-89. Disponível em: http://www. scielo.br/scielo.php?script=sci arttext\&pid=S0102-311X2013000800021\&lng=en.

16. Chaveiro N. Encontro do paciente surdo que usa Língua de Sinais com os profissionais da saúde [dissertação]. Goiânia: Universidade Federal de Goiás; 2007.

17. Vieira CM, Caniato DG, Yonemotu BPR. Comunicação e acessibilidade: percepções de pessoas com deficiência auditiva sobre seu atendimento nos serviços de saúde. Rev Eletron Comun Inf Inov Saúde [Internet] 2017 jun. [citado em 2019 mar. 15];11(2). Disponível em: https://www.reciis.icict.fiocruz.br/ index.php/reciis/article/view/1139.

18. Oliveira YCA, Celino SDM, Costa GMC. Comunicação como ferramenta essencial para assistência à saúde dos surdos. Physis [Internet]. 2015 jan./mar. [citado em 2019 mar. 17];25(1):307-20. Disponível em: https://bit.ly/2Y5Le0z.

19. Yonemotu BPR. Comunicação entre estudantes de Medicina e comunidade surda: análise de uma intervenção [dissertação]. Marília: Faculdade de Medicina de Marília; 2019.

20. Trad LAB. Grupos focais: conceitos, procedimentos e reflexões baseadas em experiências com o uso da técnica em pesquisas de saúde. Physis [Internet]. 2009 [citado em 2019 mar. 15];19(3):777-96. Disponível em: https://bit.ly/3eGwafy.

21. Freitas AR. Análise por grupos focais do instrumento para avaliação da qualidade de vida de pessoas com deficiências intelectuais e físicas (WHOQOL-DIS) traduzido para a língua brasileira de sinais [dissertação]. Goiânia: Faculdade de Medicina; 2011.

22. Lefevre F, Lefevre AMC. Discourse of the collective subject: social representations and communication interventions. Texto Contexto - Enferm. [Internet]. 2014 jun. [citado em 2019 abr. 06];23(2):502-07. Disponível em: https://bit.ly/3cB2izf.

23. Duarte SBR, Chaveiro N, Freitas AR, Barbosa MA, Porto CC, Fleck MPA. Aspectos históricos e socioculturais da população surda. Hist Cienc Saúde - Manguinhos [Internet]. 2013 dez. [citado em 2019 fev. 24]; 20(4):1713-34. Disponível em: https://bit.ly/3bus6wT.

24. Souza MFNS, Araújo AMB, Sandes LFF, Freitas DA, Soares WD, Vianna RSM. Principais dificuldades e obstáculos enfrentados pela comunidade surda no acesso à saúde: uma revisão integrativa de literatura. Rev CEFAC [Internet]. 2017 jun. [citado em 2019 jun. 14];19(3):395-405. Disponível em: https://bit. Iy/2XQG1JL.

25. Trecossi MO, Ortigara EPF. Importância e eficácia das consultas de enfermagem ao paciente surdo. Revi Enfermagem 2013;9(9):60-9.

26. Pires HF, Almeida MAPT. A percepção do surdo sobre o atendimento nos serviços de saúde. Rev Enfermagem Contemp [Internet]. 2016 [citado em 2019 jun. 14];5(1):68-77. Disponível em: https:// www5.bahiana.edu.br/index.php/enfermagem/article/view/912.

27. Nassar MRF. Comunicação e humanização: a reconstrução do relacionamento médico - paciente como critério de qualidade na prestação de serviço. Rev. Contemporânea [Internet]. 2005 [citado em 2019 maio 24];5(2). Disponível em: https://bit.ly/3czpoGz. 
28. Costa LSM, Silva NCZ. Desenvolvendo atitudes, conhecimentos e habilidades dos estudantes de medicina na atenção em saúde de pessoas surdas. Interface [Botucatu]

[Internet]. 2012 dez [citado em 2020 mar. 26];16(43):1107-17.Disponível em: https://bit.ly/2zhVNTD.

29. Costa LSM, Almeida RCN, Mayworn MC, Alves PTF, Bulhões PAM, Pinheiro VM. O atendimento em saúde através do olhar da pessoa surda: avaliação e propostas. Rev Bras Clin Med. 2009;7:166-70.

30. Cromack, EMPC. Identidade, cultura surda e produção de subjetividades e educação: atravessamentos e implicações sociais. Psicol Cienc Prof. 2004 [citado em 2019 jun. 08];24(4):68-77. Disponível em: https://bit.ly/2KpoikM. 